Ruiz, C. E., Hamlin, R. G.; \& Carioni, A. (2016). Behavioral determinants of perceived managerial and leadership effectiveness in Argentina, Human Resource Development International, Vol. 19, No. 4, 267-288. doi.org/10.1080/13678868.2016.1147778n

\title{
Behavioral determinants of perceived managerial and leadership effectiveness in Argentina
}

\author{
Abstract \\ The purpose of this empirical study was to explore the perceptions of Argentinean employees \\ about managerial and leadership effectiveness, and was guided by the following research \\ question: How do people employed in Argentinean companies behaviorally differentiate effective \\ managers from ineffective managers? A total of 42 employees from private and public sector \\ organizations in Cordoba, Argentina, were interviewed using Flanagan's (1954) critical incident \\ technique. The interviews generated 302 critical incidents of which 155 were examples of \\ positive (effective) managerial behavior, and 147 of negative (least effectivelineffective) \\ managerial behavior. The findings suggest that Argentineans perceive as effective those \\ managers who are supportive, considerate, motivating, caring, good decision makers, \\ approachable, participative, fair-minded, communicative, actively involved, and who act as role \\ models; and this challenges the widely held belief that Argentineans prefer authoritarian \\ managers over democratic ones.
}

Keywords - managerial effectiveness, managerial behavior, supervisory leadership in Argentina

\section{Introduction}

Globalization has created a need to understand how to manage people effectively across countries. The fact that an increasing number of managers are not only operating domestically but also internationally has made it imperative to understand a variety of management and leadership practices across the globe (Aimar and Stough 2007). Multinational corporations investing internationally need to understand and implement those types of management practices that are likely to be most effective in those countries where they operate. 
In the particular case of Argentina, the international levels of FDI have increased significantly over the last two decades as a result of the market reform and liberalization process initiated by the former president of Argentina, Carlos Menem, in 1989 (Keen 2010). By the beginning of the $21^{\text {st }}$ century this process had transformed the Argentinean economy into one of the most transnational economies in the world. And by 2005 it was estimated that nearly $86 \%$ of the 500 largest companies in Argentina had participation of foreign capital (Kulfas et al. 2002). As part of this process of market liberalization, Argentina joined the MERCOSUR (South Common Market) and opened its doors to Brazil, Uruguay, Paraguay, and Venezuela. Today, in addition to being part of MERCOSUR, the country also has free trade agreements with Chile, Mexico, Peru, India, Egypt, Israel, the Andean Community and the European Union (ENNI 2013).

The significant participation of foreign capital in Argentinean companies makes it imperative for international managers to understand how to properly and most effectively manage the Argentinean workforce. Consequently, they need to understand what makes managers effective in Argentina. Unfortunately, most international managers do not have the cultural knowledge and competence needed to perform adequately when managing people in countries other than their own. Therefore, they often end up returning to their home country before the assignment is over, and this early return of the international manager can be very expensive for the company (Mondy 2012).

Despite the importance that an understanding of managerial and leadership practices in Argentina has for domestic and international managers, research on this topic is very limited. Most of the studies of management and leadership have been conducted in North America and Western European countries (Hernandez-Romero 2010). Very few indigenous management and 
leadership related studies have been conducted in non-Western countries, including those located in South America such as Argentina; and thus, very little is known from indigenous research about what distinguishes effective managers from ineffective managers in these countries. In addition to the scarce research on managerial and leadership effectiveness, research on expatriates' effectiveness has mainly focused on cultural adjustment and not necessary on behaviors associated with managerial effectiveness; as stated by $\mathrm{Lu}(1995,45)$ "an effective manager has to consider behavior factors." Our study reports the findings of a recent empirical exploration of behavioral determinants of "perceived managerial and leadership effectiveness" carried out in Cordoba, Argentina.

Our indigenous study is a replication of previous studies of perceived managerial and leadership effectiveness conducted in countries which include the UK (Hamlin and Cooper 2007; Hamlin and Bassi 2008; Hamlin and Serventi 2008), China (Wang 2010) and Mexico (Ruiz et al. 2013). Following these previous studies, our use of the term 'perceived managerial and leadership effectiveness' refers to "the behavioral effectiveness of managers in performing their everyday tasks of managing and leading people" (Ruiz et al. 2013, 131). For managers, leading is an essential function when managing people (Hickman 1990; Kotter 1990; Mintzberg 2004; Tett et al. 2000; Nienaber 2010). This type of leadership, which is performed by most managers at all levels of an organization, is referred to by House et al. (2004) as "general leadership," and is different from the "strategic leadership" performed by top managers and other organizational leaders. Our use of the term indigenous research follows Tsui (2007) who defined it as any single country study that is context-specific as a result of either incorporating aspects of the national context in the theory and methods, or by taking the national context for granted which is the case for research conducted in the U.S. The central question that guided our study was: How 
do people employed in Argentinean companies behaviorally differentiate effective managers

from ineffective managers?

\section{Review of the literature}

Research on the topic of management and leadership in South American countries is very limited; and we have been unable to find any research that directly addresses the topic of managerial and leadership effectiveness in Argentina. Nevertheless, there are studies that suggest that some management practices could lead to better results than others when managing Argentinean people. For example, the findings of Hofstede's (1980) cross cultural study suggest that, based on cultural dimensions, certain managerial practices could be effective in Argentina. The cultural dimensions that he identified were 'power distance,' 'uncertainty avoidance,' 'collectivism/ individualism,' and 'masculinity/femininity.' Hofstede's findings indicate that Argentineans are high on 'uncertainty avoidance' which suggests that they do not feel comfortable taking risks and prefer to work under conditions of certainty. This translates in the workplace as employees who like to be told what to do, and who prefer managers who give clear instructions over managers who are vague and unclear. Hofstede (1980) also found that Argentineans tend to be moderate when it comes to 'power distance.' This means that they accept authority without questioning it. The finding suggests that Argentineans place a great deal of respect on executive leadership (Aimar and Sought 2007), and that Argentinean employees are more willing to accept managers who are authoritarian when compared to American employees (Luthans and Doh 2012). This view is supported by Aimar and Sought's (2007) study which suggested that in Argentina, company decisions are made at the top level, and employees at lower levels avoid contradicting their superiors. 
In regards to 'collectivism/individualism,' Hofstede's (1980) findings indicate that Argentineans are collectivist in that they place emphasis on relationships; and indeed, socialization and connections are very important for people in Argentina. As claimed by Aimar and Sought (2007), relationships may be more relevant to Argentineans than institutions, laws, or regulations. This particular finding suggests that when hiring employees Argentinean managers may rely more on an employee's references and networking rather than on more impersonal means; and it also suggests that group responsibility may be more welcomed than individual responsibility by employees in Argentina. Finally, in terms of 'masculinity/femininity,' the extent to which people value success, money and physical assets, Hofstede's findings indicate that Argentineans are highly individualistic which suggests that they place great value on physical assets, advancement, earnings, and recognition.

Following a similar line of research, Trompennars (1998) conducted a study in which the culture of 23 countries was explored based on relationship orientations. The findings of his study provide important information that could be useful when managing people in Argentina. For example, they indicate that Argentineans tend to believe that circumstances dictate how practices should be applied, which suggests that in the context of the workplace employees believe that rules should not be applied in the same way to everyone. Trust and relationships should be taken into consideration. Trompennars (1998) found that Argentineans tend to be more individualistic than collectivistic. This finding suggests that they may prefer to work individually rather than in groups, and may prefer individual responsibility over group responsibility. This contradicts Hofstede's study which indicated that Argentineans are more collectivistic than individualistic. Trompenaars' study also suggests that Argentineans are achievement oriented, which means that status in the workplace is based on performance. 
Another study that provides insight into effective management practices in Argentina is the Global Leadership Organizational Behavior Effectiveness study (GLOBE) (House et al. 2004), the findings of which suggest that in order to be an outstanding organizational leader (general manager) in Argentina, leadership behaviors which demonstrate charisma, team orientation, and a participative approach are necessary. The GLOBE study researchers also found that in order to be an effective top manager in Argentina, behaviors such as self-protective (conflict inducer, face saver, self-centered, status-conscious) and autonomous (independent, individualistic, and self-centric) should be avoided (Center for Creative Leadership 2013). However, it is important to note that the focus of the GLOBE study was "strategic leadership" as exhibited by top managers, and not the "general leadership" or supervisory leadership of everyday management practice (House et al. 2004).

Even though the afore-cited studies provide insight into the management practices that could be considered effective in Argentina, they do not directly address the question of what specifically makes Argentinean managers behaviorally effective. Indeed, these studies seem to contradict each other at times. For example, while Hofstede (1980) found that Argentineans tend to be collectivistic, Trompennars (1998) found that Argentineans are more individualistic. In addition, while Hofstede's study suggests that Argentineans are high on power distance, meaning that they prefer authoritarian managers, the GLOBE study suggests that Argentinean employees favor a participative leadership style over an authoritarian one. Thus, more research is required to address the central question posed earlier in this article. This is especially true given the increasing level of FDI and the number of international managers working in Argentina. 


\section{Theoretical framework}

This research is guided by the Implicit Leadership Theory. According to this theory, individuals have their own assumptions about what makes leaders effective and ineffective (Eden and Leviathan 1975). Individuals use their implicit theories to process situations they experience (Shaw 1990). Followers/subordinates judge the behavior of leaders/managers based on how well this behavior fits with the implicit theories that they have about the leader (Cantor and Mischel 1978). The better the fit between the perceived behavior of leaders/managers and the internal leadership prototypes (implicit theories) held by their followers/subordinates (the perceivers), the more likely they will be judged as effective or ineffective. In addition, the follower's perception of the behavior of the leader is shaped by the organizational culture (Gerstner and Day 1994) and the national culture (Helgstrand and Stuhlmacher 1999). As a result, followers from different cultures may perceive the effectiveness and ineffectiveness of the same leaders in a different manner (Chong and Thomas 1997). Discrepancies between the followers'/subordinates' and the leaders'/managers' implicit leadership theories could result in dissatisfaction and consequently a negative impact on the organization (Engle and Lord 1997).

\section{Research purpose and questions}

This indigenous empirical study in Argentina is a replication of previous studies conducted by Author 2 with other co-researchers in various culturally diverse countries around the globe. In alignment with these past studies, our study gathered empirical data derived from the observations, perceptions and judgments of both managers and non-managerial employees. The purpose of the study was to identify what Argentineans perceive as effective and ineffective managerial behavior. In following Latham and Wexley (1981), we adopted the following definitions of effective and ineffective managerial performance. Effective managerial 
performance is "behavior which you wish all managers would adopt if and when faced with a similar circumstance." Ineffective managerial performance is "behavior which, if it occurred repeatedly, or was seen once in certain circumstances, might cause you to begin to question or doubt the ability of that particular manager in that instance" (Ruiz et al. 2013, 135 and also Hamlin, 1988).

The specific research questions that we addressed are the following:

1. What managerial behaviors are perceived as effective by Argentinean managers and nonmanagerial employees?

2. What managerial behaviors are perceived as least effective or ineffective by Argentinean managers and non-managerial employees?

\section{Research methodology}

We adopted the "managerial behavior approach" to management research (Noordegraaf and Stewart 2000, 429) which consists of analyzing managerial work and behavior as it takes place within the context of an organization "with the aim of developing categories, concepts and theories on the basis of empirical evidence." We used the critical incident technique (CIT) (Flanagan 1954) to collect empirical data about managerial behavior. This technique was used by Author 2 for his original study of managerial effectiveness within UK secondary schools and for his subsequent replication studies of perceived managerial and leadership effectiveness within public, private and third (non-profit) sector organizations in the UK and various other countries. CIT is considered one of the best techniques for generating data to identify effective/ineffective managerial behavior (See Borman and Brush 1993). Moreover, as Chell (1998) argues, it allows researchers to make comparisons across cases for the purpose of demonstrating the generalizability of their findings. 


\section{Sample and data collection}

The research design attempted to collect 400 or more concrete examples (critical incidents-CIs) of effective and ineffective managerial behavior from a purposive sample of 50 or more Argentinean managers and non-managerial employees. Through a snowball sampling technique (Bryman and Bell 2003) a convenience sample of 42 people from a diverse range of organizations (20 private sector and 12 public sector) located in Cordoba, Argentina, were obtained. Of the 42 research participants, 21 were males and 21 females, 11 were nonmanagerial staff, and 31 were managers of whom 22 were first or middle level managers, and 9 were senior managers.

In order to be consistent with the original study conducted by Author 2 and his subsequent replication studies, Author 3 who collected the CIs for our study followed as closely as possible the same CIT protocol that the previous researchers had used. Prior to a CIT interview taking place, participants were informed of the purpose of the research and what was hoped to be accomplished in the CIT interview. Moreover, participants were informed of the meaning of different key terminology such as "critical," "incident," "critical incident," and "effective," and "ineffective" managerial performance. They were also informed about the questions to be asked at the interview and how to prepare for the interview as well as the code of ethics that would be applied. The interviews lasted between 60-90 minutes, during which each participant was asked to describe five incidents of specific effective managerial behavior and five incidents of specific ineffective managerial behavior that s/he had personally observed within the past 6-12 months. Those participants who were managers were not allowed to offer incidents based on their own managing/leading practices. The CIs could relate either to behavior exhibited by managers above, at the same level, or below them in the organizational hierarchy. 
For each CI, the researcher posed and strictly adhered to three standard questions, as follows: $i$ ) What was the background situation, circumstance or context that led up to the critical incident you have in mind? ii) What and in what way exactly did the subject (the manager you observed) do/say or not do/say that was either effective or ineffective? and iii) What was the specific result or outcome of the critical incident that you have described, and. on reflection, why do you perceive/judge this to be an example of "effective" or "ineffective" managerial behavior/ managerial performance? The answers were recorded as far as possible using the same words used by the CIT informant when s/he described the critical incident. The CIT interviews generated 302 usable critical incidents. These CIs were translated from Spanish to English by Author 3 (native Spanish speaker).

\section{Data analysis}

The first step in the data analysis process was to subject the collected CIs to first level content analysis using open coding at the semantic level in order to identify the unit of meaning (code) of each incident, and to disentangle any CI that contained more than one unit of meaning (Miles and Huberman 1994). No additional CIs emerged from this procedure. Out of the 302 coded CIs, 155 were examples of positive (effective) managerial behavior and 147 were examples of negative (ineffective) managerial behavior. The CIs were then subjected to second level content analysis using axial coding to identify any convergence of meaning of the identified codes, and accordingly to group them into discrete behavioral categories containing a minimum of 3 and a maximum of 12 CIs. As a result of this step, three CIs were found to have nothing in common with any other CI. This may have been the result of them not having been widely exhibited and/or observed, or they could have been idiosyncratic behaviors manifested by individual managers. Hence, in accordance with the common CIT protocol used in previous 
replication studies; these CIs were eliminated from the data set. Each emergent behavioral category was then interpreted, and the identified meaning held in common with the constituent CIs was described in essence by a behavioral statement (BS); this was then used to label the category.

Trustworthiness of the Findings. Whenever doubts arose during the CIT data collection phase about the critical aspect of a described CI, these were clarified there and then. Furthermore, the CIT interviewees were asked by Author 3 during or at the end of their interviews to confirm (validate) the meaning of the CIs being recorded. Additionally, whenever doubts arose in Author 3's mind whilst transcribing some of the recorded CIs, the CIT interviewees were contacted to further clarify/confirm their precise meaning. The CIs were originally collected in Spanish and subsequently translated into English by Author 3 who is fluent in Spanish and English. Then the English version was back translated into Spanish by a native English speaker who, as a university professor of Spanish, is fluent in both languages. To ensure the internal validity (credibility) and reliability (dependability) of our findings we applied a form of investigator triangulation (Easterby-Smith et al. 1991). Initially, this involved Author 2 carrying out independently the initial content analysis of the English translated CIs. Subsequently, his analyses and interpretation of the CIT data were sent to Author 1 for crosscode checking (Gibbs, 2007) to minimize researcher bias. Where there were differences of perception and judgment, these were critically examined and reconciled until a consensus was reached.

\section{Results}

This section presents the result of subjecting the 299 CIs to content analysis. 
Overall sixty-nine (69) behavioral categories (behavioral statements-BSs) were deduced, of which 32 were related to positive (effective) and 37 to negative (least effective/ineffective management behavior. For better illustration, four tables are used to present the derived behavioral statements. Table 1 provides a list of the 32 positive (effective) BSs and Table 2 lists the 37 negative (least effective/ineffective) BSs. In addition, examples of CIs that support a few INSERT Tables $1 \& 2$ ABOUT HERE

selected BSs are provided in Table 3, and to exemplify the overall sense of the type of CIT data from which the BSs were derived, we provide in Table 4 the content of two CIT "data strips" INSERT Tables 3 \& 4 ABOUT HERE

relating to one positive (effective) critical incident and one negative (least effective/ineffective) critical incident. Each "data strip" shows the background context to the particular concrete example (critical incident) of observed managerial behavior, and also the resulting consequences/outcomes that caused the two respective CIT interviewees to perceive and judge them as effective and least effective or ineffective respectively.

Based on the results of our study it seems that managers in Argentinean organizations are perceived effective by their respective peers, superiors, and subordinates when, for example, they (i) are approachable, flexible and understanding of employees' needs and problems; (ii) are fair decision makers and take into consideration employees' suggestions as well as support employees' decisions, (iii) are good motivators by providing rewards and recognition as well as procuring a friendly and respectful work environment; (iv) care about employees doing a good job by supporting employees, providing guidance, professional development, providing recommendations for work improvement and by making sure employees have all the resources to do their work; and (v) are concerned about the image of the company by making sure 
employees provide excellent customer service. On the other hand, Argentinean managers are perceived least effective or ineffective when, for example, they (i) are close-minded, difficult to talk to, not understanding of employees' problems, not inclusive, and authoritarian; (ii) are unfair and inconsiderate, do not reward hard work; (iii) are laissez-fair, lack of care about work, do not care about employees' working conditions; (iv) show a negative attitude, are arrogant and rude by making employees feel bad and treating customers badly; (v) have poor organization and communication skills; and (vi) are incompetent and unprofessional as well as unethical by breaching the company's policies.

\section{Discussion}

The findings of our study could be useful to better understand those managerial behaviors that are perceived as effective by Argentinean employees. Our research suggests that an effective manager in Argentina is perceived as someone who possesses attributes such as being supportive, motivating, caring, considerate, participative, approachable, fair-minded, communicative, actively involved, and being a decision maker and role model.

The results challenge previous studies which suggest that Argentinean employees feel comfortable with authoritarian managers. In sharp contrast to the findings of Hofstede (1980) and Aimar and Stough (2007), our findings suggest that authoritarian managers may not be very effective in Argentina. Based on the perceptions of our research participants, effective managers are those who are participative and involve employees in decision making. We suggest this may be more consistent with the reality because it is well known that Argentineans enjoy sharing their opinions, and they also enjoy argumentation (Aimar and Stough 2007). Therefore, a manager who involves employees in decision making and asks for their input will align better with the mindset of typical Argentineans. In fact, Perez and Gonzalez (2007) suggest that the apparent 
acceptance by subordinates of superiors' decisions, which characterizes South American cultures, does not necessarily mean that employees will fully accept and follow their superiors' orders.

Our findings relating to the managerial behaviors (including supervisory leadership behaviors) exhibited by senior, middle, and first line managers are consistent with the GLOBE study findings regarding the participative organizational leader behaviors associated with effective strategic leadership. In addition, they are consistent with the ineffective leadership behaviors identified by the GLOBE study such as being self-centric, independent, and individualistic in which they could potentially inhibit outstanding leadership. These findings suggest that the supervisory leadership behaviors associated with effective first, middle, and senior level managers are similar to the behaviors associated with effective top managers and other organizational leaders in Argentina.

The findings of our empirical study are similar to those that have resulted from previous studies of perceived managerial and leadership effectiveness conducted in other non-Western countries, including China (Wang 2010) and Egypt (see Hamlin, Nassar and Wahba, 2010). This convergence of findings across multiple cases suggests the existence of universalistic managerial and leadership behaviors that are considered effective across countries regardless of cultural differences. The emergence of a potential universal set of managerial and leadership behaviors suggested by the findings of this study could be the result of cultural changes taking place at a faster pace than previously predicted (Steel and Taras 2010).

A distinctive finding resulting from this study compared to findings from prior replication studies of perceived managerial and leadership effectiveness is the role that image plays on managerial and leadership effectiveness. Our findings suggest that effective managers in 
Argentina should care not only about the image and reputation of the company, but also about their personal image. The following participants' comments are examples of the role that image, or personal appearances, could play in managerial and leadership effectiveness:

"The director is always well dressed and clean. This sets a very good example for the rest of us."

"We all must dress very professionally, not only when we go to court but also when we are at the firm...we never know when a new client might arrive, and we want to send the right image; the manager always emphasizes this aspect [personal image] and it works well."

"Well dressed and educated, with very good manners with our clients"

In summary, our results suggest that effective managers in Argentina are those who are considerate, good decision makers, participative, approachable, supportive, role models, motivating, caring, fair-minded, communicative, and actively involved.

\section{Practical implications}

We suggest our findings on effective and least effective/ineffective managerial behavior in Argentina could be useful for both domestic and international managers by helping them to make better decisions about how to effectively lead an Argentinean workforce. In addition, they could assist human resource development (HRD) professionals in the design of effective management development programs. Effective management is necessary for the survival of the organization. Organizations need effective managers in order to implement strategic initiatives. Therefore, it is imperative that organizations have management development programs in place in order to maintain effective managerial and leadership practices (Amagoh 2009). HRD professionals from international MNCs with establishments in Argentina could find our results 
beneficial when preparing expatriates for Argentinean based assignments. Addressing in the expatriates' training programs, those managerial behaviors that are perceived effective in the host country, would help expatriates to make the right decisions when working with their subordinates and peers. As indicated by Amagoh (2009), effective management development programs must take into consideration the complexity of the global environment. In this case, management development programs designed to enhance expatriates' skills to effectively lead in Argentina, should take into account the perceptions of the Argentinean workforce regarding what behaviorally distinguishes effective managers from ineffective managers.

We suggest it is important for domestic and international managers to be aware of how their performance is perceived by their peers, superiors and subordinates, because discrepancies between the subordinates' and the managers' ideas about effective and ineffective management/leadership could result in dissatisfaction, and consequently, have a negative impact on the organization (Engle and Lord 1997). Hence, identifying Argentineans' perceptions of effective managerial behaviors including supervisory leadership behaviors could help HRD departments to better prepare domestic and international executives to lead Argentinean organizations in a more effective manner.

\section{Limitations and recommendations for future research}

Our study has three main limitations. The first is related to the amount of CIT data obtained which, in our original research design, was planned to be 400 or more CIs from 50 or more research participants. However, due to prevailing logistical and time constraints on Author 3 , in the event she was able to collect only 302 usable critical incidents through the snowball sampling process. Therefore, it is likely that there are other behavioral categories that have not been identified. 
The second limitation is the fact that the study focused on the observations and judgments of native Argentinean participants only. Therefore, their perceptions and the resulting portrayal of effective and least effective/ineffective managers in Argentina are likely to be valueladen from just one cultural perspective. Hence, we suggest these perceptions could be triangulated by also exploring perceived managerial and leadership effectiveness in Argentina from the perspective of international/expatriate managers who work in Argentina, or other people who have constant interaction with Argentinean managers.

The third limitation is related to the generalizability of the findings. All the participants were located in Cordoba, Argentina, and although the data collected from them provided rich insights into perceived managerial and leadership effectiveness in one part of the country, it cannot be assumed that the findings are generalizable and transferable to the whole of Argentina.

It is advised that a replication of this study in other regions of Argentina be conducted. Building and administering a 'behavioral item questionnaire' to a large population in Argentina, based on the behavioral categories identified in this study, could overcome the generalizability limitation of the study.

\section{Conclusion}

The purpose of this emic replication managerial behavior study was to explore the perceptions of managers and non-managerial employees regarding the behavioral determinants of managerial and leadership effectiveness and ineffectiveness in Argentina. By focusing on Argentina, the resulting indigenous findings contribute to a growing body of empirical evidence from equivalent replication studies carried out in Colombia (Torres, et al. 2015) and Mexico (Ruiz, et al. 2013) that is helping to develop a better understanding of perceived managerial and leadership effectiveness in Latin America. The findings of these two prior studies and of our 
study lend support to those who theorize the existence of generic effective and ineffective managerial behaviors relevant and usable across countries. Furthermore, our Argentinean findings are consistent with those resulting from the afore-cited replication studies previously conducted in various non-Latin American countries including China, Egypt, Germany, Romania and the UK. Overall, the cumulative evidence suggests that certain effective (and least effective/ineffective) management and leadership behavioral practices may be context-general and applicable in multiple countries. It also points toward the possible existence of a 'universal' model of perceived managerial and leadership effectiveness; but this is speculation that has yet to be demonstrated empirically.

\section{References}

Aimar, C., and S. Stough. 2007. "Leadership: Does Culture Matter? Comparative Practices between Argentina and the United States of America.”.Academy of Educational Leadership Journal 11(3): 9-43.

Amagoh, F. 2009. “Leadership Development and Leadership Effectiveness.” Management Decision 47(6): 989-999.

Borman, W. C., and D. H. Brush. 1993. "More Progress Toward a Taxonomy of Managerial Performance Requirements." Human Performance 6(1): 1-21.

Bryman, A., and E. Bell. 2003. Business Research Methods. Oxford: Oxford University Press.

Cantor, N., and W. Mischel. 1979. "Prototypes in person Perception.” Advances in Experimental Social Psychology.” 12: 3-53.

Center for Creative Leadership. 2013. "Leader Effectiveness and Culture: The GLOBE Study.” Accessed October 8, 2013. http://www.ccl.org/leadership/pdf/assessments/GlobeStudy.pdf 
Chell, E. 1998. "Critical Incident Technique." in Qualitative Methods and Analysis in

Organizational Research: A Practical Guide, edited by G. Symon and C. Cassell, 51-72. London: Sage.

Chong, L. M., and D. C. Thomas. 1997. "Leadership Perceptions in Cross Cultural Context: Pakeha and Pacific Islanders in New Zealand.” The Leadership Quarterly 8(3): 275-293.

Easterby-Smith, M., R. Thorpe, and A. Lowe. 1991. Management Research: An Introduction. London: Sage.

Eden, D., and U. Leviatan. 1975. "Implicit Leadership Theory as a Determinant of the Factor Structure Underlying Supervisory Behavior Scales.” Journal of Applied Psychology 60(6): 736-741.

Engle, E., and R. Lord. 1997. "Implicit Theories, Self-schemas, and Leader-Member Exchange.” Academy of Management Journal 40(4): 988-1010.

ENNI. 2013. "Argentina: Free Trade Agreements (FTA) and International Relations." Accessed November, 24, 2013. http://en.reingex.com/Argentina-FTA-Agreements.shtml (accessed 24 November 2013)

Flanagan, J. C. 1954. “The Critical Incident Technique.” Psychological Bulletin 51(4): 327-358.

Gerstner, C., and D. V. 1994. "Cross-cultural comparison of leadership Prototypes." Leadership Quarterly 5(2): 121-134.

Gibbs, G. 2007. Analyzing Qualitative Data. London: Sage.

Hamlin, R. G. 1988. “The Criteria of Managerial Effectiveness in Secondary Schools. CORE: collected and original resources in education." The International Journal of Educational Research in Microfiche 12(1): 1-221. 
Hamlin, R. G. 2004. “In Support of Universalistic Models of Managerial and Leadership Effectiveness.” Human Resource Development Quarterly 15(2): 189-215.

Hamlin, R. G., and N. Bassi. 2008. "Behavioral Indicators of Manager and Managerial Leader Effectiveness: An Example of Mode 2 Knowledge Production in Management to Support Evidence-Based Practice.” International Journal of Management Practice 3(2): 115-130.

Hamlin, R. G., and D. J. Cooper. 2007. "Developing Effective Managers and Leaders within Healthcare and Social Care Contexts: An Evidence-Based Approach.” In HRD in the Public Sector: The Case of Health and Social Care, edited by S. Sambrook and J. D. Stewart, 187-212. London: Routledge.

Hamlin, R.G., M. Nassar, and K. Wahba. 2010. "Behavioural Criteria of Managerial and LeadershipEffectiveness within Egyptian and British Public Sector Hospitals: An Empirical Study and Multiple-Case/Cross-Nation Comparative Analysis.” Human Resource Development International, 13 (1), pp 43-64.

Hamlin, R. G., and S. Serventi. 2008. “Generic Behavioral Criteria of Managerial Effectiveness: An Empirical and Comparative Study of UK Local Government.” Journal of European Industrial Training, 32(4): 285-230.

Helgstrand, K., and A. F. Stuhlmacher. 1999. "National Culture: An Influence on Leader Evaluations.” The International Journal of Organizational Analysis 7(2): 153168.

Hernandez-Romero, E. 2010. "Characteristics of Mexican Leaders in Complex Organizations in Monterrey Mexico: An Exploratory Study of the Perceptions of Human Resource Executives.” PhD diss., Pepperdine University. 
Hickman, C. 1990. Mind of a Manager, Soul of a Leader. New York: Wiley.

Hofstede, G. (1980). Culture's Consequences. Sage Publications, Beverly Hills, CA.

House, R. J., P. J. Hanges, M. Javidan, P. W. Dorfman, and V. Gupta. 2004. Culture, Leadership, and Organizations: The GLOBE study of 62 societies. London: Sage.

Ireland, D., and M. Hitt. 2005. “Achieving and Maintaining Strategic Competitiveness in the 21st Century: The Role of Strategic Leadership.” The Academy of Management Executive 19(4): 66-77.

Keen, C. 2010. "The Internationalization of Small- and Medium-Sized Enterprises from Argentina." PhD diss., McGill University, Montreal, Canada.

Kotter, J. 1990. A Force for Change: How Leadership Differs from Management. New York: Free Press.

Kulfas, M., F. Porta, and A. Ramos. 2002. "Inversión Extranjera y Empresas Transnacionales en la Economía Argentina. CEPAL, Serie Estudios y Perspectivas Nro. 10.

Latham, G. P., and K. N. Wexley. 1981. Increasing Productivity through Performance Appraisal. Reading, MA: Addison-Wesley.

Luthans, F., and J. P. Doh. 2012. International Management: Culture, Strategy, and Behavior. $8^{\text {th }}$ ed. New York: McGraw-Hill Irwin.

Miles, M. B., and A. M. Huberman. 1994. Qualitative Data Analysis. Thousands Oak, CA: Sage. Mintzberg, H. 2004. Managers not MBAs: A Hard Look at the Soft Practice of Managing and Management Development. San Francisco, CA: Berrett-Koehler.

Mondy, W. 2012. Human Resource Management $11^{\text {th }}$ ed. Upper Saddle River, NJ: Prentice Hall. Nienaber, H. 2010. “Conceptualization of Management and Leadership.” Management Decision 48(5): 661-675. 
Noordegraaf, M., and R. Stewart. 2000. "Managerial Behavior Research in Private and Public Sectors: Distinctiveness, Disputes and Directions." Journal of Management Studies 37(3): 427-443.

Perez-Floriano, L., and J. Gonzalez. 2007. "Risk, Safety and Culture in Brazil and Argentina: the Case of TransInc Corporation.” International Journal of Manpower 28(5): 403-417.

Ruiz, C., J. Wang, and R. Hamlin. 2013. "What Makes Managers Effective in Mexico?" Leadership and Organization Development Journal 34(2): 130-146.

Shaw, J. B. 1990. “A Cognitive Categorization Model for the Study of Intercultural Management." Academy of Management Review 15(4): 626-645.

Steel, P., and V. Taras. 2010. "Culture as a Consequence: A Multi-Level Multivariate MetaAnalysis of the Effects of Individual and Country Characteristics on Work-Related Cultural Values." Journal of International Management 6(3): 211-233.

Tett, R. P., H. A. Gutterman, A. Bleier, and P. Murphy. 2000. "Development and Content Validation of a "Hyperdimensional" Taxonomy of Managerial Competence." Human Performance. 13: 205-251.

Trompenaars, F., and C. Hampden-Turner. 1998. Riding the Waves of Culture: Understanding Diversity in Global $2^{\text {nd }}$ ed. New York: McGraw-Hill.

Tsui, A. S. 2007. "From Homogenization to Pluralism: International Management Research in the Academy and Beyond." Academy of Management Journal 50: 1353-1364.

Wang, J. 2010. “Exploring Managerial Effectiveness: Empirical Evidence from China.” In the Proceedings of the Academy of Human Resource Development 2010 International Research Conference, edited by C. Graham and K. Dirani, Knoxville, TN. 


\section{Table 1}

\section{Positive (Effective) Behavioral Statements}

1) Expects employees to exhibit a high standard of appearance and behavior to ensure the right image is sent out, and thereby protect the reputation of the business (e.g. impeccable dress, organization, cleanliness, confidentiality of information)

2) Sets and communicates clear objectives and outcome expectations, and gives clear directions/instruction on how to achieve them

3) Monitors the performance of employees (and of self) and takes action to maintain or improve it and/or to address identified sub-standard behavior

4) Takes action to check and maintain productivity and the quality of products and customer service

5) Takes action to ensure customers/clients are properly taken care of by employees (or by self if necessary)

6) Makes sure employees have up to date resources/technology and are in a safe working environment

7) Provides advice, guidance and/or ideas to help/support employees

8) Recognizes the hard work, good performance and exceptional achievements of individual employees through financial or non-financial reward (e.g extra pay/bonus or pay rise or payment in kind)

9) Pays all employees well, with regular incremental increases, and/or general benefits, or bonuses allocated according to seniority.

10) Recognizes, praises, and shows his/her appreciation when employees hard work and perform well

11) Leads by example in ensuring a good image and reputation of self and of his/her company (e.g. in terms of dress, cleanliness, manners, demeanor, trustworthiness)

12) Manager delegates responsibilities for projects to employees and/or empowers then to make their own decisions in the way they operate

13) Is fair in the way s/he treats her/his employees

14) Recognizes and treats employees with respect as individuals and/or as equals

15) Does and says things that make employees feel good about themselves and/or feel important

16) Visits and/or contacts staff who are sick or have a close family member who is sick o check how they are and to offer all necessary help

17) Allows employees to work flexible hours provided their performance is not affected

18) Allows employees 'leave of absence' to attend to domestic emergencies or personal health matters

19) Shows care and consideration for the feelings and personal well-being of employees

20) Shows care and kindness for employees and other people

21) Helps employees learn from their mistakes

22) Acts as mentor, coach and/or role model 
23) Encourages and/or supports employees to study and learn more so as to develop themselves personally and professionally

24) Provides or facilitates training and professional development opportunities

25) Actively listens to/talks with employees who have queries or doubts

26) Is always seen in a good mood which also makes employees feel good at work

27) Does things that make employees feel important and part of a team/community

28) Takes every opportunity to say nice things about every individual employee

29) Socializes with employees which builds a trusting relationship

30) Seeks opinions of his/her employees before making decisions

31) Gets employees together in departmental meetings and/or ad hoc meetings when problem situations arise to discuss specific and/or general issues and to share ideas and differences

32) Always ensures employees are paid on time

\section{Table 2}

\section{Negative (Least Effective/Ineffective) Behavioral Statements}

1) Exhibits poor planning and self-organization

2) Omits or fails to communicate clearly orders, instructions or concerns about employee performance

3) Shows lack of care and consideration when an employee (or a close family member ) is sick

4) Shows lack of interest, respect or feeling for employees or other people

5) Autocratically bypasses the organization's spending rules and does what s/he wants

6) Excludes any employee from being involved in decision making

7) Never listens to and/or disregards the ideas and opinions of employees

8) Having delegated managerial responsibilities to a subordinate s/he finds difficulty letting go and/or still makes direct contact with employees over their heads

9) Autocratic and overly controlling behavior

10) Treats employees unequally

11) Treats employees unfairly and/or is unreasonably harsh

12) Exhibits favoritism

13) Behaves without consideration of the negative impact on his/her employees including intrusion or undesired encroachment into their private lives 
14) Is unreliable in decision making and/or exhibits inconsistent/contradictory behavior

15) Exhibits selfish/self-centered behavior

16) Engages in self-serving defensive behavior at the expense of others

17) Engages in manipulative behavior to get rid of and/or replace an employee s/he does not want

18) Engages in unprofessional/unethical behavior

19) Exhibits rude and/or impatient behavior

20) Undermines employees by ridiculing them

21) Criticizes and/or says things to employees in ways that put them down and make them feel uncomfortable

22) Reprimands/criticizes individuals or groups of employees in front of others

23) Instigates, solicits and/or engages in gossip about individual employees and/or customers

24) Gets upset or furious over issues and then screams at employees

25) When asking employees to work extra hours or work extra hard does so in ways that makes them feel threatened/coerced

26) Periodically comes to work in a 'bad mood' and exhibits behavior which inhibits or prevents effective communication taking place with employees

27) Procrastinates in making decisions or taking agreed action

28) Exhibits poor interpersonal and persuasive communications skills with employees, superiors, and/or clients

29) Exhibits behavior that reveals a lack of competence and/or a poor standard of appearance/performance

30) Avoids or ignores taking action to address sub-performance issues or problem situations affecting employees

31) Is distant and/or disengaged with his/her job and shows no interest in participating and/or helping himself or his employees

32) Deprives employees of desirable information, backing, and/or support

33) Deprives employees of positive and/or negative feedback on performance and/or of incentives to perform or funding for personal development

34) Fails to recognize and reward employees for hard work and/or extra effort

35) Fails to recognize and/or remunerate employees according to their specific individual contribution and/or worth to the organization

36) Keeps to himself or tries to hide from employees most of the tips and commissions earned by them

37) Is closed to new ways of doing thing, and/or exhibits rigid thinking and inflexible behavior 


\section{Table 3}

\section{Examples of Positive and Negative Behavioral Statements Showing an Indicative Sample of Supporting Critical Incidents}

\section{Behavioral Statements}

Seeks opinions of his/her employees before making decisions

Allows employees to work flexible hours provided their performance is not affected

Gets upset or furious over issues and then screams at employees

Exhibits poor interpersonal and persuasive communications skills with employees, superiors, and/or clients
Indicative Supporting Critical Incidents

He asks for everybody's opinion. He doesn't believe that he knows everything. He brings his ideas too

Every time an important decision is to be made our boss calls us all to his office for a discussion. He always asks for your opinion and what it is that we see as we go one way or another way. This is like sharing power and most of the time with excellent results

When it comes to decision making he is always careful to let us express our opinion

My boss is very flexible with the hours I work. Sometimes I get to my office very early, sometimes late. As long as I work the amount of hours I need to work per week, he doesn't complain

He doesn't care about the time we get there or we leave. The only thing he cares is that we finish what we are supposed to finish

If you need to leave early, she lets you do it. The only thing is that then you know that during that week you need to make up the time you missed

It seems as if the only way to communicate with them is by screaming. They do not know any other way and also it seems that the employees must always be happy because of their job there

Every year, when it is time to pay taxes, he gets so upset that everybody is scared in the office. He usually takes it out on us. He acts like he never knows that taxes time is coming and he gets furious every year

When she goes to other schools and calls the office to ask about something, and if you do not know the answer she will scream so loud that the all office will hear her

It is very difficult to talk with him. He is not a bad person but he lacks "social skills

When I have an idea or something to request to make a better deal and my boss needs to go to his boss to ask, the answer is always NO. I think that he presented things in a wrong way so all my ideas are rejected 
He is so isolated that he doesn't participate in any of the important meetings with important clients

Table 4

Examples of Critical Incidents with Background and Consequence

Background Critical Incident Consequence

There was a delay on the time the car was supposed to be ready. The client was upset.

area.
The Sales Manager was informed and he personally called the clients to back up his employees' explanation and better explain the reason for the delay and explore different ways in which the problem could be fixed

The chief of the mechanic area asked in a very threatening manner and screaming that they should continue working until they receive the necessary "parts" in one or two days. Even if it was not safe
This was very good from the part of the Manager, because it showed that he is backing up the sales person and in general the way we relate to customers in the company.

The manager of the mechanic should have seen that that part was going to be needed, and in that specific moment to stop all labor in order to protect the workers. And then to stop production until the part that was missing arrives. We felt that he did not care at all about our safety. 